\title{
Meso-Experimental Study on Tensile Characteristics of Clay
}

\author{
Yi Zhou, ${ }^{1,2}$ Meng Cui $\left(\mathbb{D},{ }^{3,4,5}\right.$ Dequan Zhou, ${ }^{1}$ Xiaojia Wang, ${ }^{2}$ and Xiao Fu ${ }^{3,5}$ \\ ${ }^{1}$ School of Civil Engineering, Changsha University of Science \& Technology, Changsha, Hunan 410114, China \\ ${ }^{2}$ Poly Changda Engineering Co., Ltd., Guangzhou, Guangdong 510620, China \\ ${ }^{3}$ School of Civil and Architectural Engineering, Nanchang Institute of Technology, Nanchang, Jiangxi 330099, China \\ ${ }^{4}$ Key Laboratory of Hydraulic and Waterway Engineering of the Ministry of Education, Chongqing Jiaotong University, \\ Chongqing 400074, China \\ ${ }^{5}$ Jiangxi Province Key Laboratory of Hydraulic \& Civil Engineering Infrastructure Security, Nanchang, Jiangxi 330099, China
}

Correspondence should be addressed to Meng Cui; cmyfwy@126.com

Received 30 August 2020; Revised 1 March 2021; Accepted 21 March 2021; Published 30 March 2021

Academic Editor: Payam Shafigh

Copyright $\odot 2021$ Yi Zhou et al. This is an open access article distributed under the Creative Commons Attribution License, which permits unrestricted use, distribution, and reproduction in any medium, provided the original work is properly cited.

\begin{abstract}
This paper presents an experimental study on the meso-structure change of clay using an innovative testing system. It aims to evaluate the tensile characteristics of clay. The testing system designed in this paper includes a tensile loading device, an image acquisition device, and an image processing program, which can collect and process the meso-structural images of the soil sample and predict the location of tensile fracture zone with a small preloading. The tests were conducted with three different observation zones, including the tensile fracture zone (Zone 1), the adjacent area of tensile fracture zone (Zone 2), and the areas away from the tensile fracture zone (Zone 3). The results show that the development of cracks is continuous but not linear until tensile failure in Zone 1, and the cracks emerge but stop developing in Zone 2 with the penetration of the cracks in Zone 1, while there is only an overall deviation without any cracks in Zone 3. The variety of mesostructural quantitative parameters in Zone 1 can be divided into three stages: stable stage, rapid change stage, and failure stage. The changes of parameters in Zone 2 show a similar law with those in Zone 1, but the variation is smaller due to the cessation of cracks. The parameters in Zone 3 essentially remain unchanged throughout the whole procedure. According to the test results, the whole stretching process of clay can be divided into the sprouting, the development, and the penetration of cracks.
\end{abstract}

\section{Introduction}

Under the influence of external factors, the basic stress state of soil includes compressed state, sheared state, and stretched state. The compression and shear characteristics of soil have been mainly studied in traditional soil mechanics because the early civil engineering work focused mostly on the ground. However, as the underground space projects have been thriving in recent years, some new engineering accidents occur constantly due to the tensile failure of soil, such as the ground collapse during subway construction, settlement basin or settlement funnel during the dewatering excavation of the foundation pit, and landslide caused by the tensile cracks on the top of the soil slope. Therefore, the research on tensile properties of soil is gaining more and more attention [1].
At present, the research achievements on the tensile properties of soils are mostly concentrated on the invention of macroscopic tensile testing devices and related experiment $[2,3]$, and the tensile tests on different soils have been carried out, such as clayey soil [4, 5], frozen soil [6], recompacted soil $[7,8]$, reinforced soil $[9,10]$, and unsaturated sands [11]. The stretching methods mainly include direct stretching [12-15] and indirect stretching [16-18]. Tang et al. $[19,20]$ developed a strain-type vertical tensile device to test the tensile strength of soil samples and fiberreinforced soil. Cui et al. [21, 22] invented a new type of the uniaxial tensile system and sample preparation device, and based on this, the macroscopic mechanical properties of clay under different initial conditions were comprehensively studied. Lü et al. [23] invented a simple uniaxial stretcher, in which the load was applied step by step by weight, and the 
sample was cylindrical, and by the stretcher, the tensile properties of the expansive and shrinking soil were studied. Satoshi and Kohei [24] invented a uniaxial tensile device including temperature control facilities to study the tensile strength of frozen soil. Zhang et al. [25] invented a geotechnical tensile device and tested the tensile strength of three different geotechnical materials. Zhu et al. [26] invented a tensile tester based on the modification of triaxial shearing apparatus, by which the tensile strength and shear strength of unsaturated clay were analyzed contrastively.

In general, the research on tensile properties is not indepth due to the limitation of available test equipment. For example, most research results focused on the relationship between tensile strength and other indicators on a macro level, such as compactness, water content, and shear strength.

Existing studies have proved that multiscale research can help reveal the deformation and failure mechanism; hence the micro and meso-testing technology [27-32] that has been used in other fields can be applied to the tensile testing of soil. Based on this, a testing system was developed by the authors to study the mesostructural changes of the soil during stretching [33], and the related experiments are carried out in this paper to discuss the evolution law of the mesostructural form and quantitative parameters in different areas during the whole stretching process.

\section{Testing System and Operation}

The innovative mesostructure change testing system developed in this study includes a tensile loading device, an image acquisition device, and an image processing program.

2.1. The Tensile Loading Device. The tensile loading device is used to apply tensile loading and measure the tensile stress and displacement of the sample. The tensile loading device and sample preparation mold are shown in Figures 1(a) and 1(b), respectively. In the sample preparation mold, the stretch section mold is connected with both sides through the dovetail groove. So, the length of the stretch section can be adjusted, as shown in Figure 1(c), and it is the initial length.

In the tensile test, the stretching speed can be set, and the accuracy can reach $0.001 \mathrm{~mm} / \mathrm{min}$. Therefore, the tensile displacement can be calculated by the stretching speed and time.

2.2. The Image Acquisition Device. The image acquisition device is used to photograph mesostructure in different regions of the sample under different tensile stresses, and it includes a long distance telecentric microscope, a threedimensional console, and a camera. The microscope and three-dimensional console are shown in Figure 2(a), and the transmission path of image signal is shown in Figure 2(b).

2.3. The Image Processing Program. The image processing program can enhance, fuse, stitch, and split the captured images and extract the quantitative parameters, which can describe the features of porosity and particles. The details of the image processing technology are as follows.

2.3.1. Image Enhancement. The isotropic sharpening spatial filter was established based on Laplacian operator, and the following formula is adopted to express the enhanced image:

$$
f_{h b}(x, y)= \begin{cases}A f(x, y)-\nabla^{2} f(x, y), & A \text { is positive, } \\ A f(x, y)+\nabla^{2} f(x, y), & A \text { is negative }\end{cases}
$$

where $f_{h b}(x, y)$ is the function of enhanced image, $f(x, y)$ is the function of initial image, $\nabla^{2} f(x, y)$ is the discrete Laplace transform function of $f(x, y)$, and $A$ is the central coefficient.

The above formula can be realized by the composite mask, which is shown in Figure 3. The value of $A$ is the key, and it is the standard Laplace transform when $A=1$. Based on the images captured by the image acquisition device, it is found that the image enhancement effect is the best when $A=1.7$ through the comparison of multiple groups, and two examples are shown in Figure 4.

2.3.2. Image Fusion. The multiresolution fusion technology based on wavelet transform is adopted to solve the depth of field, and the processing steps are as follows:

Step 1. Decompose the initial image by two-dimensional wavelet transform to get the low frequency approximation part and the high frequency detail part of the image, and the quantity of decomposition layer is three. As shown in Figure 5, $C_{3}$ is the low frequency approximation part, reflecting the overall information of the image, and $D_{j}^{k}(j=1,2,3 ; k=h, v, d)$ represents the horizontal, vertical, and diagonal components in the high frequency detail part, reflecting the detailed information of the image.

Step 2. In the wavelet transform domain of two different images, compare the high frequency coefficients of each component at different decomposition scales and then choose and save the larger absolute value for each coefficient, as shown in the following formula:

$$
w_{j, k}^{\wedge}=\left\{\begin{array}{l}
w_{j, k}^{1}, \operatorname{abs}\left(w_{j, k}^{1}\right)>\operatorname{abs}\left(w_{j, k}^{2}\right), \\
w_{j, k}^{2}, \operatorname{abs}\left(w_{j, k}^{1}\right) \leq \operatorname{abs}\left(w_{j, k}^{2}\right),
\end{array}\right.
$$

where $w_{j, k}^{1}$ and $w_{j, k}^{2}$ are the wavelet coefficients at component $k$ and scale $j$ of the two images, respectively.

Step 3. Choose and save the larger one between the approximation coefficients by wavelet transform of the two initial images, which is expressed in the following formula: 


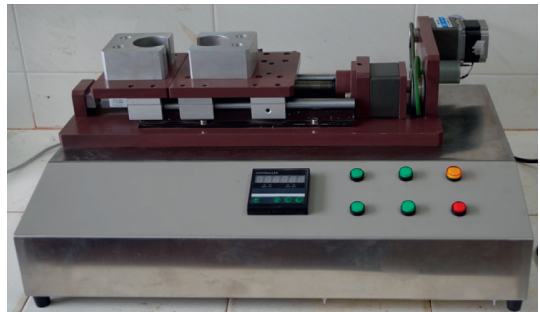

(a)

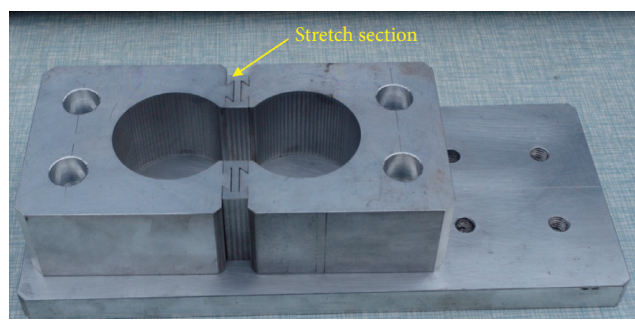

(b)

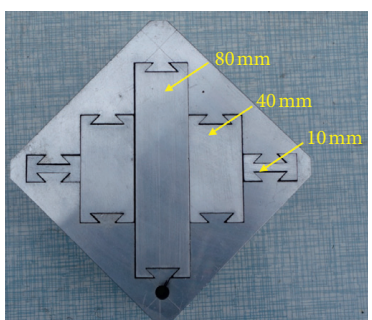

(c)

FIGURE 1: Tensile loading device and sample preparation mold: (a) tensile loading device; (b) sample preparation mold; (c) stretch section mold.

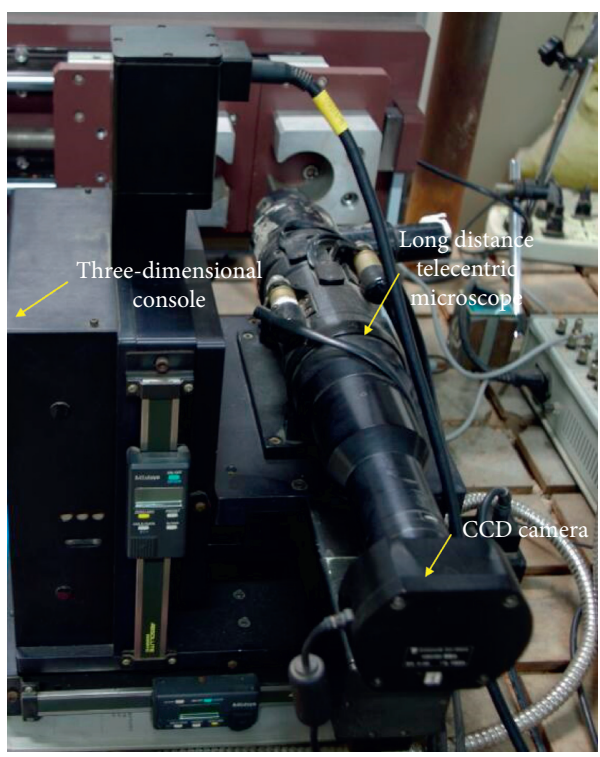

(a)

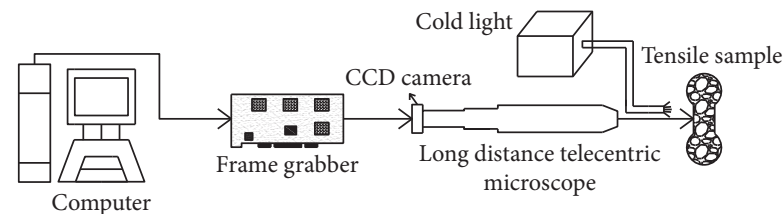

(b)

FIgURE 2: The image acquisition device: (a) microscope and three-dimensional console; (b) transmission path of image signal.

\begin{tabular}{|c|c|c|}
\hline-1 & -1 & -1 \\
\hline-1 & $A+8$ & -1 \\
\hline-1 & -1 & -1 \\
\hline
\end{tabular}

FIGURE 3: The Laplace transform composite mask. 


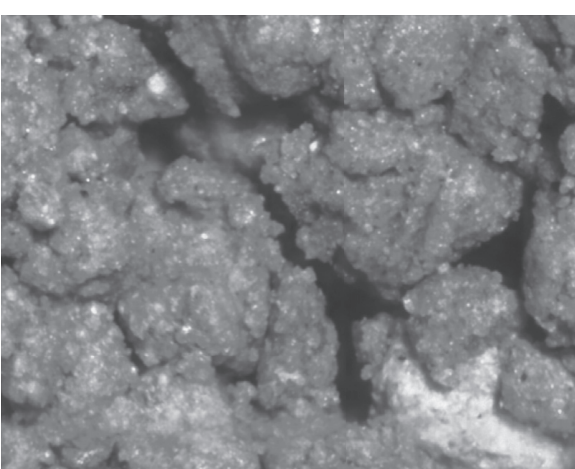

(a)

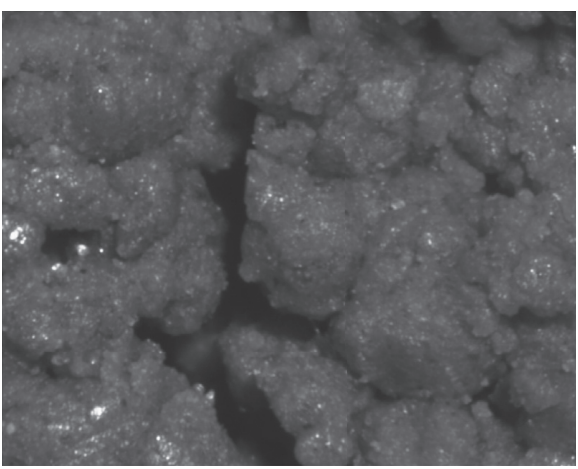

(c)

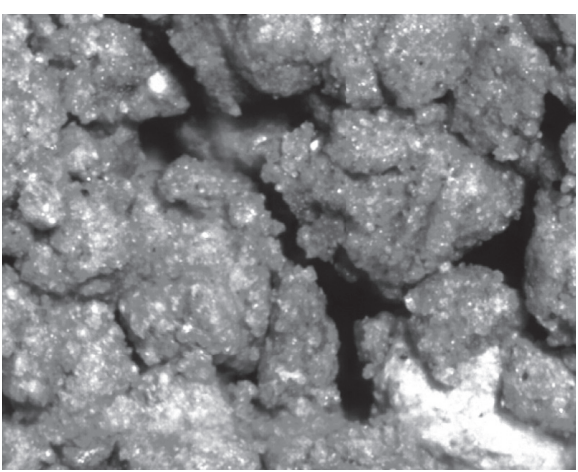

(b)

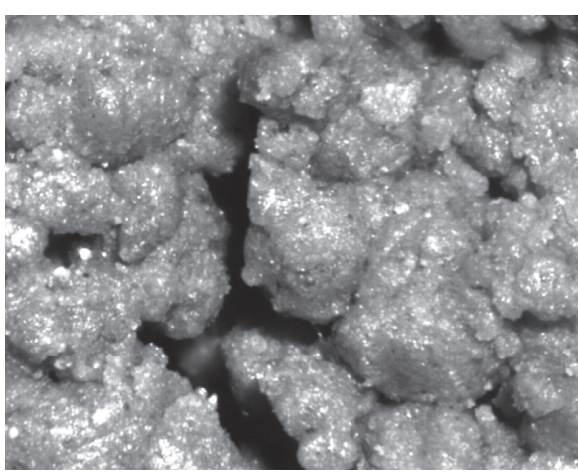

(d)

FIgURe 4: Two examples with image enhancement: (a) initial image 1; (b) enhanced image 1; (c) initial image 2; (d) enhanced image 2.

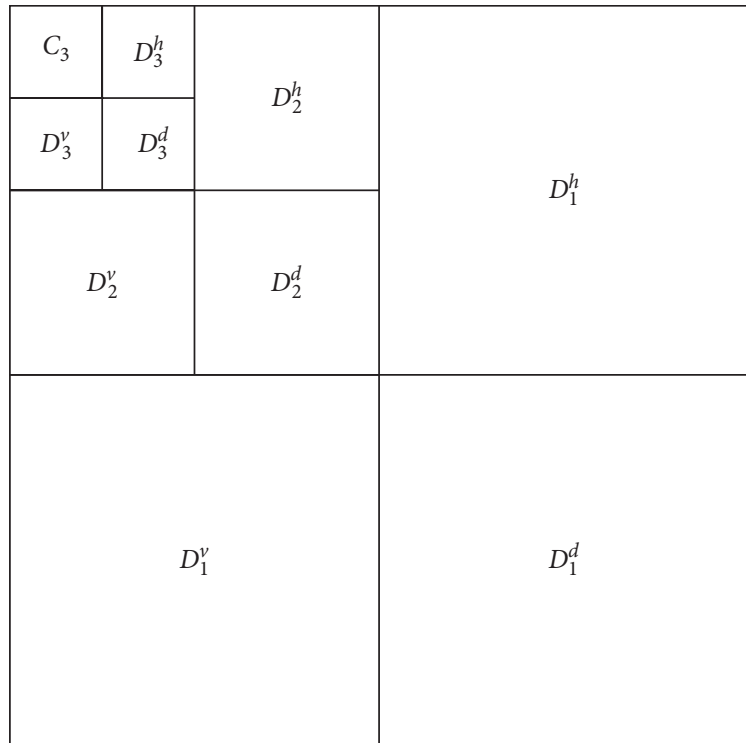

FIGURE 5: Wavelet decomposition diagram (three layers). 


$$
\widehat{C}_{3}=\left\{\begin{array}{l}
\stackrel{1}{C_{3}}, \stackrel{1}{C_{3}}>\stackrel{2}{C_{3}}, \\
\stackrel{2}{C_{3}}, \stackrel{1}{C_{3}} \leq \stackrel{2}{C_{3}},
\end{array}\right.
$$

where $\stackrel{1}{C_{3}}$ and $\stackrel{2}{C}_{3}$ are the approximation coefficients by wavelet transform of the two initial images and $\widehat{C}_{3}$ is the approximation coefficient of the fused image.

Step 4. Perform two-dimensional inverse wavelet transform on all the wavelet coefficients and approximation coefficients obtained by formulae (3) and (4), and then we can get the fused image.

One example is shown in Figure 6, in which Figure 6(a), 6(b), and 6(c) are three initial images with different focal length while Figure 6(d) is the fused image, and the area circled by red line is the clear part of each image.

2.3.3. Image Mosaic. Image mosaic is to expand the image range on the premise of ensuring partial clarity. It mainly includes four parts: image collection and preprocessing, image feature information extraction, image feature information registration, and image fusion, and image feature information registration is the key.

As shown in Figure $7, f_{1}(x, y)$ and $f_{2}(x, y)$ are two images to be stitched. The size of each captured image is $m \times n$, and it is divided into two parts: reference part and registration part. The size of registration part is a quarter of the entire image, and three feature templates are selected for registration. The three feature templates are numbered $\mathrm{M} 1$, $\mathrm{M} 2$, and M3, and the size of each feature template is $5 \times 5$. Since there is no rotation, the linear search method can meet the requirement, and the search area of three feature templates is numbered S1, S2, and S3, respectively. In the process of registration, the areas covered by the three templates are numbered F1, F2, and F3, so the sizes of F1, F2, and F3 are all $5 \times 5$. The registration formula is based on the minimum mean square error, and it can be evaluated as follows:

$$
\mathrm{MSE}=\min \left\{\frac{1}{3} \times\left[\frac{1}{25} \sum_{i=1}^{5} \sum_{j=1}^{5}\left(\mathrm{M}_{i j}-\mathrm{F} 1_{i j}\right)^{2}+\frac{1}{25} \sum_{i=1}^{5} \sum_{j=1}^{5}\left(\mathrm{M} 2_{i j}-\mathrm{F} 2_{i j}\right)^{2}+\frac{1}{25} \sum_{i=1}^{5} \sum_{j=1}^{5}\left(\mathrm{M}_{i j}-\mathrm{F}_{i j}\right)^{2}\right]\right\},
$$

where MSE is the minimum mean square error, and both $M_{i j}$ and $F_{i j}$ are the pixel value at the point of $i$ row and $j$ column.

One example is shown in Figure 8, in which Figures 8(a), $8(\mathrm{~b}), 8(\mathrm{c})$, and $8(\mathrm{~d})$ are four initial images, and Figure $8(\mathrm{e})$ is the stitched image. It can be seen that it is smooth in overlap area among the four images, and there is no seam.

Based on the system, the evolution process of the mesostructure and the corresponding quantitative parameters during tensile failure can be analyzed. The whole testing system is shown in Figure 9.

2.4. Test Operation. The location and size of the observation area are the key points of the experiment, and obviously the evolution zone of tensile fracture zone is the most important. In order to fix the observation area before the experiment, the digital speckle correlation method was adopted which can identify the area with greater deformation by the calculation of relative displacement field [31]. The adopted correlation coefficient calculation formula to match the subregions before and after deformation is as follows:

$$
C=\frac{\left\{\sum \sum[(f-\langle f\rangle) \cdot(g-\langle g\rangle)]\right\}^{2}}{\sum \sum(f-\langle f\rangle)^{2} \cdot \sum \sum(g-\langle g\rangle)^{2}},
$$

where $f(x, y)$ and $g\left(x^{\prime}, y^{\prime}\right)$ represent the gray distribution function of the subregion before and after deformation, respectively, $C=1$ indicates that the two subregions are completely related, and $C=0$ indicates that the two subregions are not related.
With the use of the digital speckle correlation method, the location of tensile fracture zone and the observation area by minute preload can be determined. Figure 10 shows a calculation example, which proves that this method is feasible.

On the other hand, the size of the observation area should be fixed according to the purpose and conditions prior to the experiment. The lens has 10 times zoom, and the resolution ratio of captured image is $1280 \times 1024$. In order to obtain a clear mesostructure of soil, the field size of the microscope is about $1.0 \mathrm{~mm}^{2}$ according to the image quality of soil, so we should take several photos to cover the whole observation area. In the process of the preliminary test, it is appropriate to select a $6 \times 3$ observation range, which means six horizontal fields and three vertical fields will be captured in a stress. In addition, the depth of the field is obvious because the surface of the soil sample is uneven, so three to five images will be captured in a field to obtain a clear image by image fusion processing. Therefore, a total of fifty-four to ninety images will be captured under a certain state of tensile stress.

Also, the loading step should be fixed before the test. According to the mechanical characteristics of the soil sample, the loading step ranges from $0.02 \mathrm{~mm}$ to $0.05 \mathrm{~mm}$ in the initial stretching phase, and after that it reduces to $0.01 \mathrm{~mm}$. The whole tensile load must be applied at least fifteen times to ensure the continuity of test data.

2.5. System Detection and Calibration. It is necessary to detect and calibrate the system prior to the test, mainly including the tensile loading device and image acquisition 


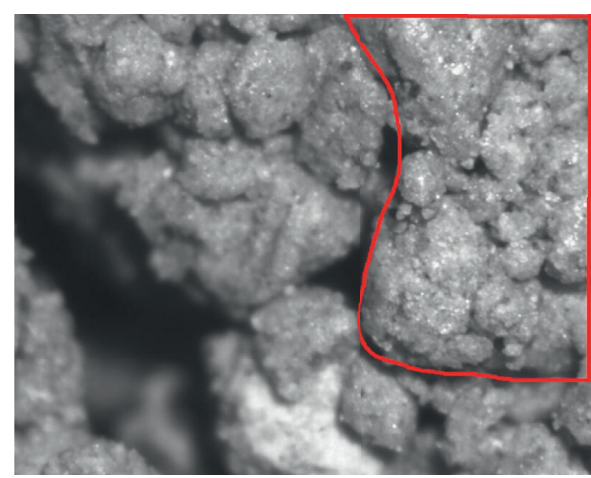

(a)

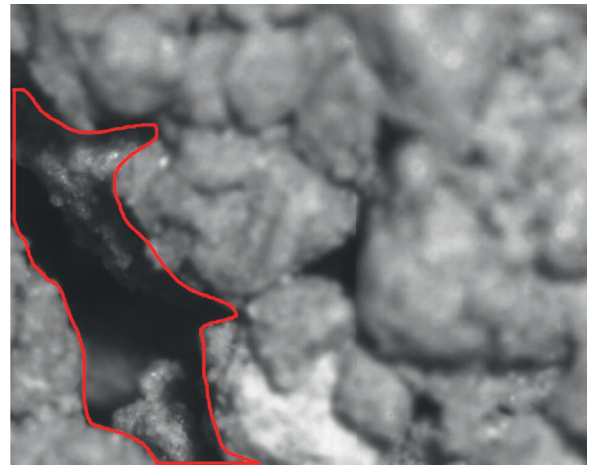

(c)

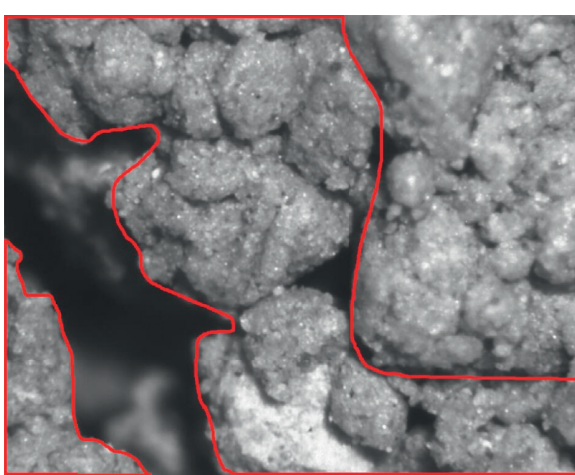

(b)

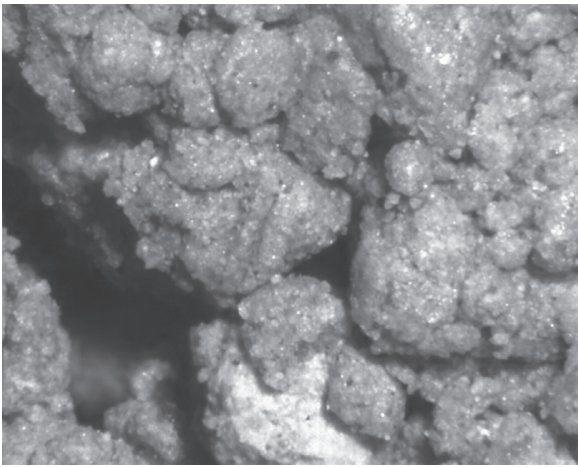

(d)

FIgURE 6: Image fusion example.

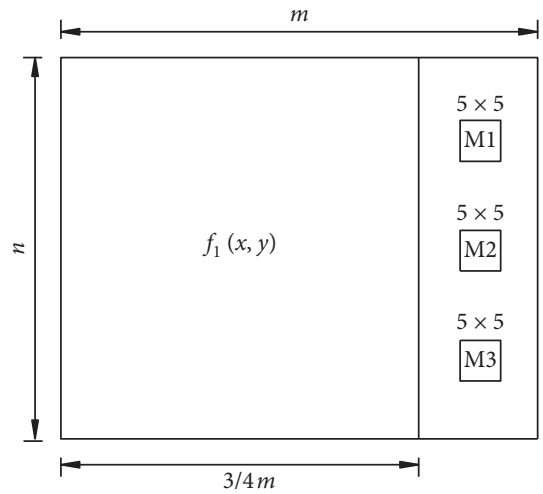

(a)

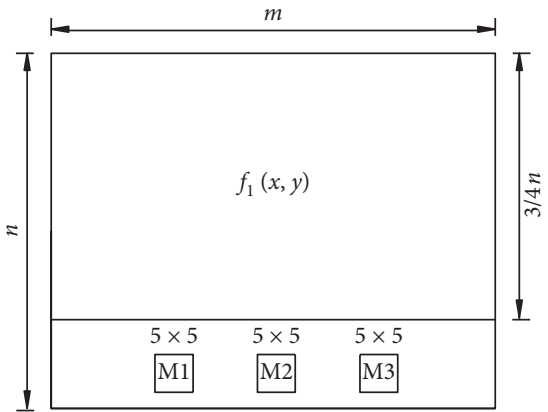

(c)

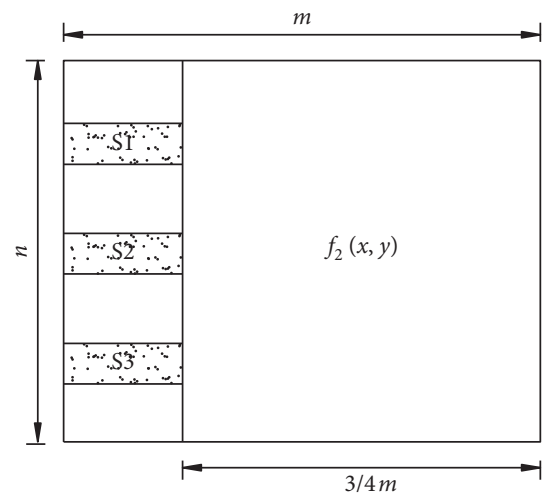

(b)

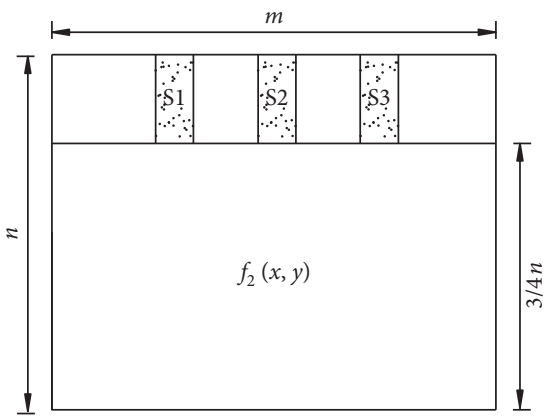

(d)

FIgURE 7: The schematic diagram of image mosaic: (a, b) image mosaic in left and right directions; (c, d) image mosaic in upper and lower directions. 


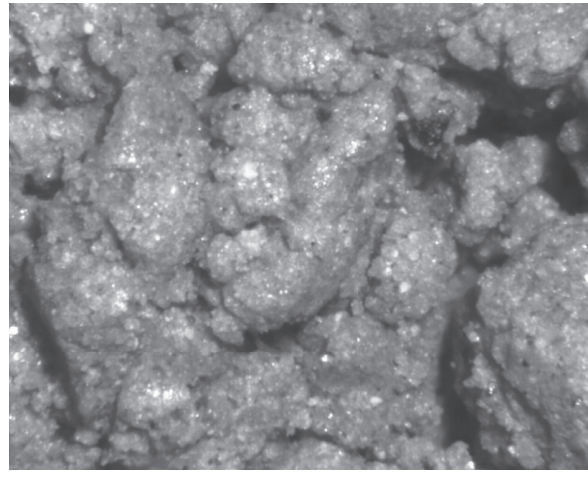

(a)

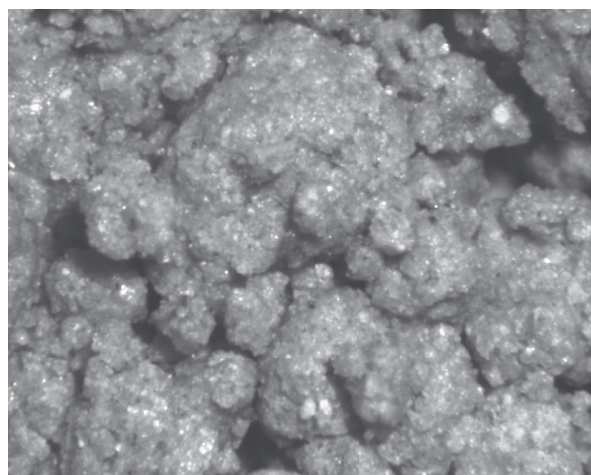

(c)

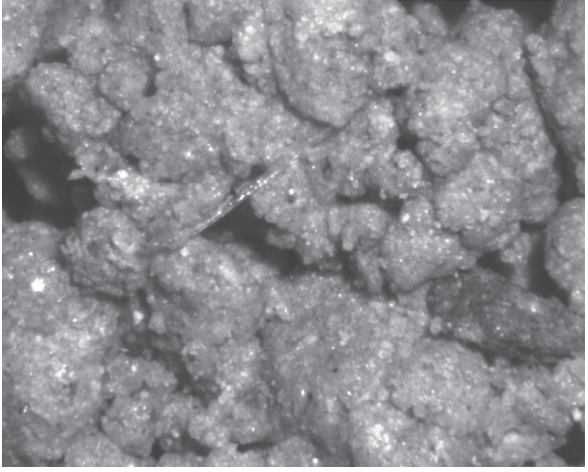

(b)

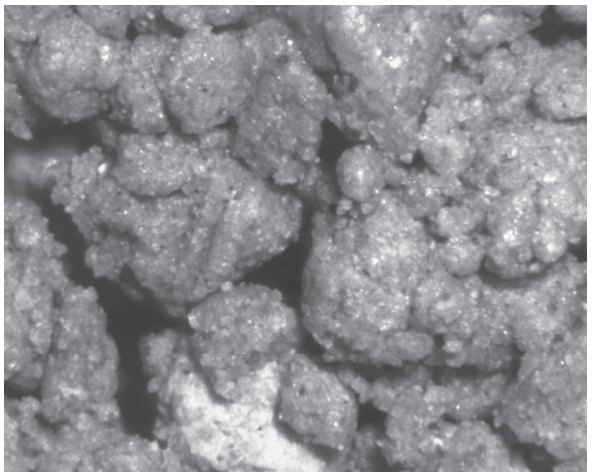

(d)

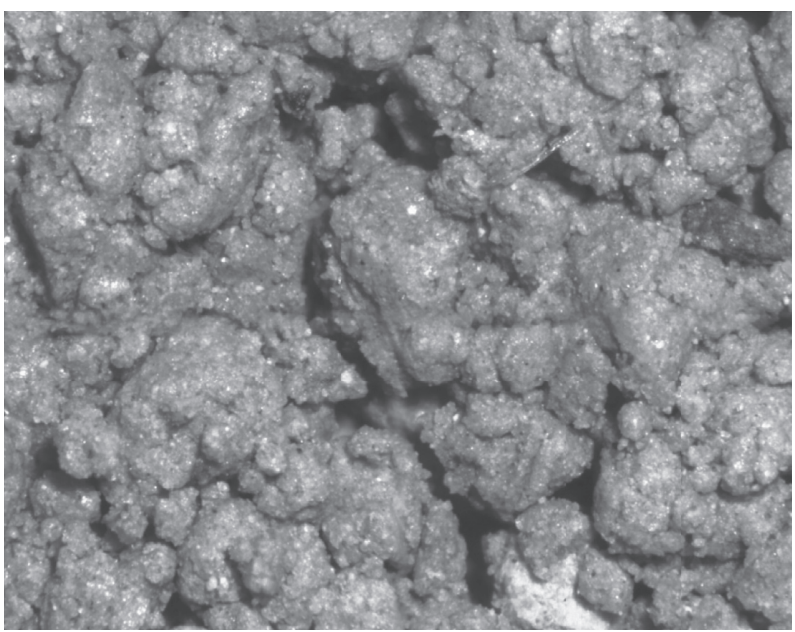

(e)

Figure 8: Image mosaic example.

device. For the tensile loading device, we need to detect the connection of each component and calibrate the tension sensor and displacement sensor. For the image acquisition device, the detection includes the connections of long distance telecentric microscope, CCD camera, magnification controller, and computer and the connections of three-dimensional console, console driver, and another computer. Except for the connection, both the brightness of cold light and the accuracy of the stepper motor should be detected. The calibration is mainly used to limit the field size of the microscope to $1.0 \mathrm{~mm}^{2}$ by setting up a scale ruler on the surface of soil sample.

\section{Test Preparation}

3.1. Test Soil. The clay is selected in the test, and by geotechnical test, the physical index and grain size distribution of the clay were measured and are shown in Table 1 and Figure 11, respectively. Through calculation, the index of colloidal activity IA $=5.17$. 


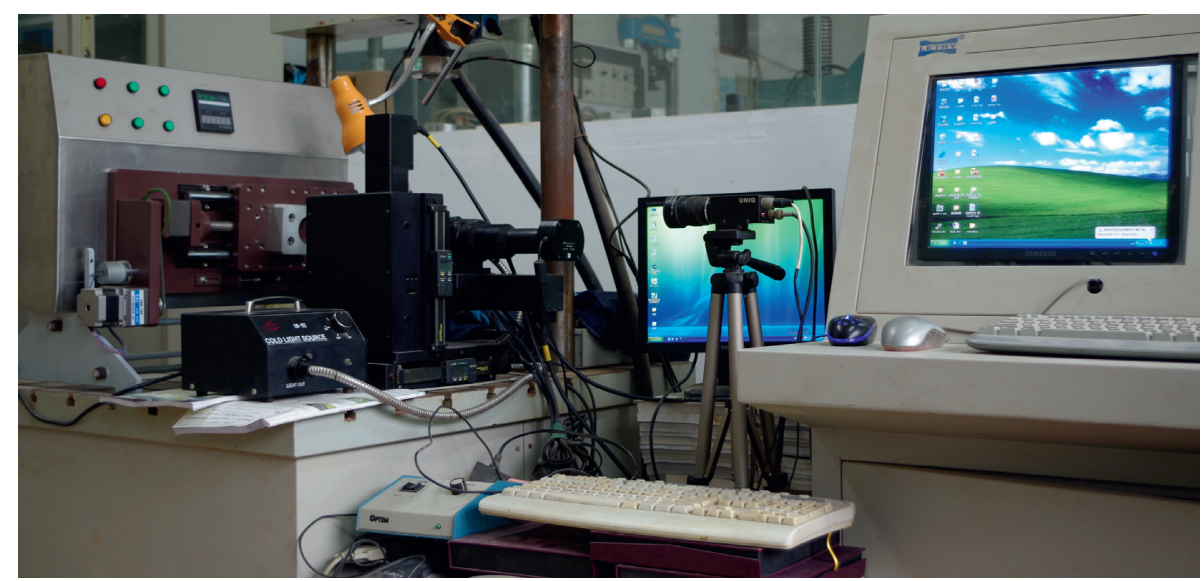

FIGURE 9: The overall picture of the testing system.

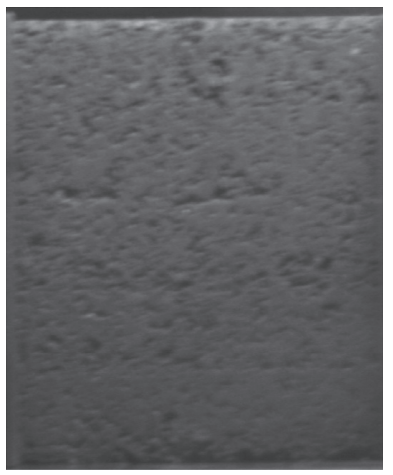

(a)

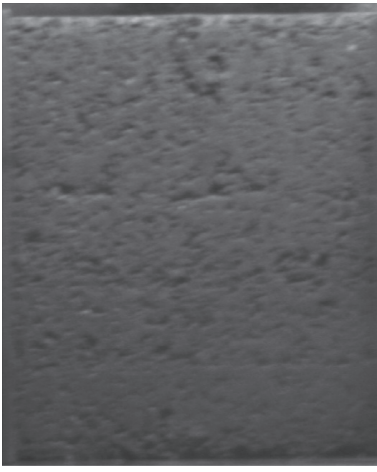

(b)

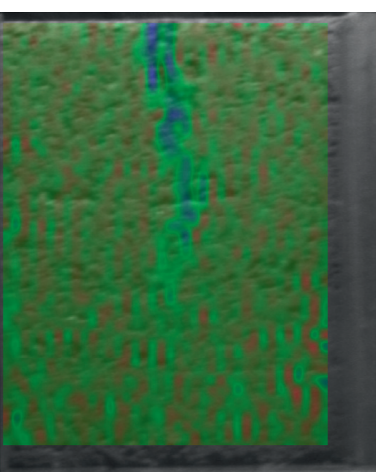

(e)

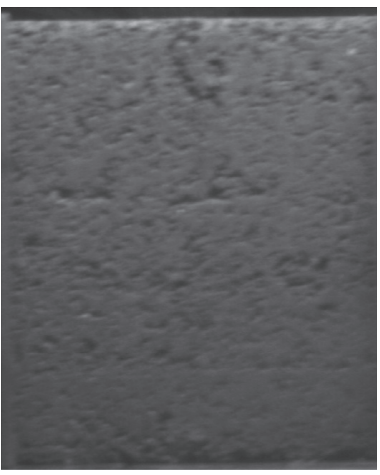

(c)

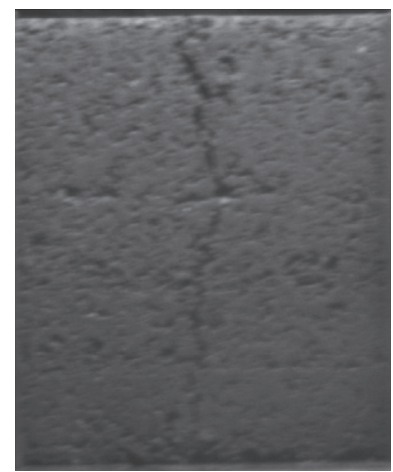

(f)

FIgURE 10: The calculation example of displacement field: (a) initial image; (b) horizontal tensile displacement is $0.005 \mathrm{~mm}$; (c) horizontal tensile displacement is $0.01 \mathrm{~mm}$; (d) gradient cloud map of the displacement field in (b); (e) gradient cloud map of the displacement field in (c); (f) tensile failure form.

TABle 1: The basic physical index of test soil.

\begin{tabular}{lcccc}
\hline Specific gravity & Liquid limit $(\%)$ & Plastic limit $(\%)$ & Maximum dry density $\left(\mathrm{g} / \mathrm{cm}^{3}\right)$ & Optimum moisture content $(\%)$ \\
\hline 2.78 & 38.5 & 23.0 & 1.75 & 19.5 \\
\hline
\end{tabular}

The chemical elements of the test soil were tested with EX-250 EDS, which are shown in Table 2. From Table 2, we can see that the clay minerals mainly include $\mathrm{SiO}_{2}, \mathrm{Al}_{2} \mathrm{O}_{3}$, $\mathrm{Fe}_{2} \mathrm{O}_{3}, \mathrm{FeO}, \mathrm{K}_{2} \mathrm{O}, \mathrm{MgO}$, and so on.
The SEM images of soil sample with $90 \%$ compactness are shown in Figure 12, in which it can be seen that the structure of test soil is stromal, the particle is flaky, the edge is irregular, and the structural unit is nondirectional. Also, 


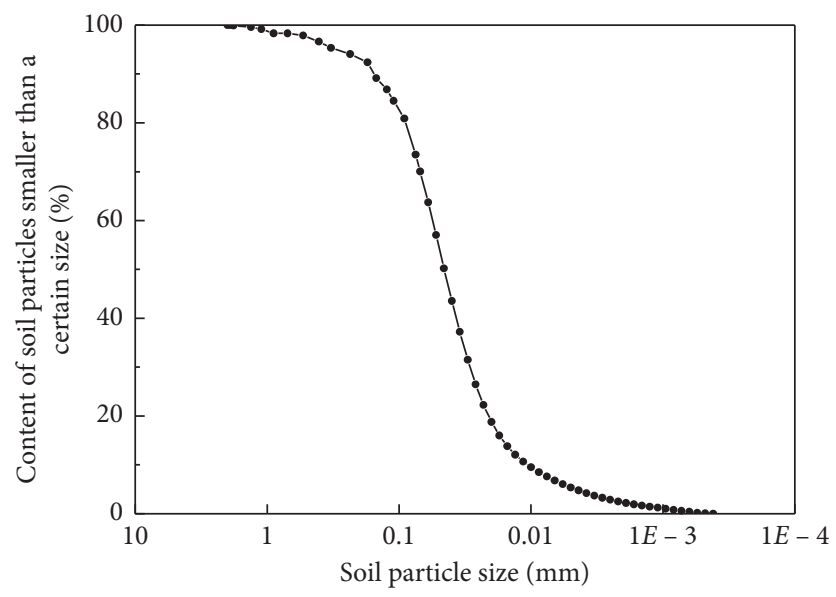

FIgURE 11: The grain size distribution of test soil.

TABLE 2: The chemical element composition of test soil.

\begin{tabular}{lccccccccc}
\hline Chemical element & $\mathrm{O}$ & $\mathrm{C}$ & $\mathrm{Si}$ & $\mathrm{Al}$ & $\mathrm{Fe}$ & $\mathrm{K}$ & $\mathrm{Mg}$ & $\mathrm{Ca}$ & $\mathrm{Na}$ \\
\hline Content (\%) & 62.89 & 16.49 & 11.67 & 4.11 & 2.47 & 0.99 & 0.51 & 0.34 & 0.28 \\
\hline
\end{tabular}

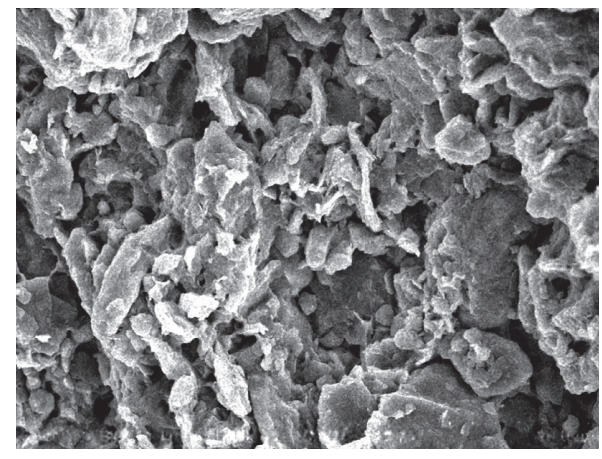

(a)

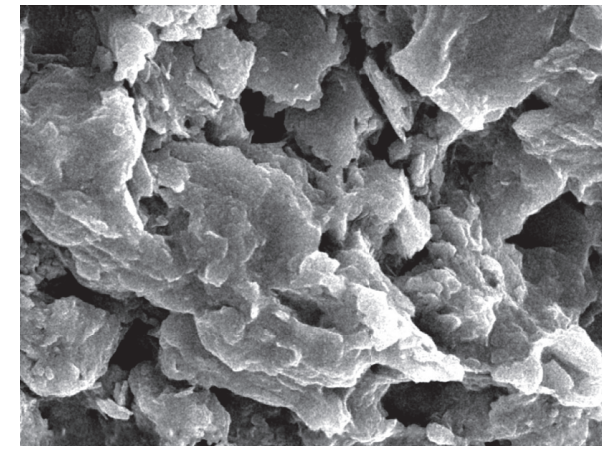

(b)

FIgURE 12: The SEM images with 90\% compactness: (a) 1000 times; (b) 3000 times.

we can see that cement exists among particles, which makes the soil have tensile strength.

\subsection{Sample Preparation. The sample preparation steps are as} follows:

(1) Dry and crush the original soil, then pass the treated soil through a $2 \mathrm{~mm}$ sieve, and measure the water content of soil under the sieve.

(2) Calculate the weight of required soil and water according to the following test plan, spray and mix the water evenly for several times, then pack it up in a plastic bag, and bury it by wet sand for 24 hours.

(3) Install sample preparation mold and apply lubricating oil to the inner surface of the mold. Compact the soil in five layers evenly and shave the soil between layers.

(4) Remove the mold of the stretch section and connect the mold of both ends to the test platform of tensile loading device by bolts.

3.3. Test Plan. Compactness and water content are two indicators that can affect the mechanical properties and structure of soil greatly, so the two indicators are selected as variables in the test. Combining the value of optimal moisture content, the water content and compactness in the actual project, and the mesostructural image quality of the soil, six representative soil samples with different initial conditions are selected, which are shown in Table 3. For other test variables, stretch section length of soil sample 
TABLE 3: The parameters of soil samples.

\begin{tabular}{lcccc}
\hline Number & Compactness $(\%)$ & Water content $(\%)$ & Density $\left(\mathrm{g} / \mathrm{cm}^{3}\right)$ & Weight $(\mathrm{g})$ \\
\hline 1 & 85 & 15.5 & 1.718 & 2.021 \\
2 & 100 & 15.5 & 1.851 & 329.87 \\
3 & 90 & 17.5 & 1.953 & 358.05 \\
4 & 95 & 17.5 & 1.987 & 375.04 \\
5 & 95 & 19.5 & 2.126 & 381.42 \\
6 & 100 & 21.5 & 408.20 \\
\hline
\end{tabular}

was set as $40 \mathrm{~mm}$, and the stretching rate was set as $0.01 \mathrm{~mm} / \mathrm{min}$.

\section{Test Results and Discussion}

4.1. Meso-Structural Form. Test results show that the changes of soil structure in different zones are different. To show the differences, it needs to fuse, enhance, and stitch the captured images to obtain a clear and large field image. The processed image of soil sample with $100 \%$ compactness and $15.5 \%$ water content is shown in Figure 13.

Three representative zones are marked in Figure 13. Zone 1 represents the tensile fracture zone; Zone 2 represents the adjacent area of tensile fracture zone; and Zone 3 represents an area far away from the tensile fracture zone. The evolution of mesostructure in three zones will be discussed in the following sections.

4.1.1. Zone 1. In Zone 1, the continuous images under different tensile displacements of the soil sample with $95 \%$ compactness and $15.5 \%$ water content are shown in Figure 14, in which $L$ represents tensile displacement.

From Figure 14, it can be seen that the mesostructural form changes with the tensile displacement, and the change is continuous but not linear. The cracks develop slowly in the initial stretching stage as shown from Figures 14(a) to 14(c) but develop rapidly after the main crack is formed as shown from Figures 14(d) to 14(f). That is because the tensile displacement is borne by the whole stretch section in the initial stage and there is no crack at this time due to the existence of tensile strength. Tensile stress is like searching for the weak position within the soil sample, and once the weak position is locked, the crack will emerge and evolve rapidly. At this time, the cracks are usually more than just one, but when the main crack forms, other cracks will stop evolving, and the main crack will grow to be the tensile fracture zone.

In addition, combining with the changes of tensile stress and displacement, we can also see that when the main crack forms, the tensile stress is close to the peak. With the main crack continuously growing, the tensile stress will reach the peak and then drop rapidly. The rate of crack evolution and the value of peak stress depend on the initial conditions of soil sample.

4.1.2. Zone 2. In Zone 2, the continuous images under different tensile displacements of the soil sample are shown in Figure 15. It can be seen that the crack grows in the initial stage but stops when the tensile displacement reaches $0.110 \mathrm{~mm}$. That is because the crack does not penetrate other cracks to be the main crack, which will grow continuously.

By comparing the images of Figures 15(d), 15(e), and 15(f), we can also see that the crack rebounds slightly after it stops growing. That is because the soil around the tensile fracture zone unloads after the formation of main crack. By the observation during the whole test, we can also see that there are many cracks distributing around the tensile fracture zone, and their development is almost as same as that of the crack in Figure 14.

4.1.3. Zone 3. In Zone 3, the continuous images under different tensile displacements of the soil sample are shown in Figure 16. It can be seen that the mesostructure of soil sample does not change from beginning to end, and the crack does not grow at all. However, the soil in the field moves horizontally, that is, because the loading device is unidirectional.

4.2. Meso-Structural Quantization Parameters. As can be seen from Figures 14-16, the form of the soil pores and particles has changed during the stretching process. To quantify this change, the mesostructural quantization parameters are extracted from the processed image by using the self-developed image processing program, including particle orientation, particle distribution fractal dimension, porosity, and pore distribution fractal dimension. These parameters are used to describe the features of particle and pore.

The definition of particle orientation is as follows:

$$
H=1+\sum_{i=1}^{n} P_{i}[\alpha, \beta] \log _{n} P_{i}[\alpha, \beta],
$$

where $H$ is the particle orientation, $[\alpha, \beta]$ is the azimuth interval, $P_{i}[\alpha, \beta]$ is the probability that the azimuth of the longest chord of the soil particle is $\operatorname{in}[\alpha, \beta]$, and $n$ is the number of azimuth intervals.

It can be seen that the value range of $H$ is $[0,1]$, and the larger the value of $H$, the better the order of particle arrangement. In the paper, the value of $n$ is eight, and the range of each interval is the same $45^{\circ}$. In the process of parameter extraction, the grid with $3 \times 3$ pixels is used to divide the entire image, and $H$ can be calculated after counting the azimuth of particles in each grid.

The definition of distribution fractal dimension is based on box-counting dimension, and the calculation method of particle distribution fractal dimension is the same as that of 


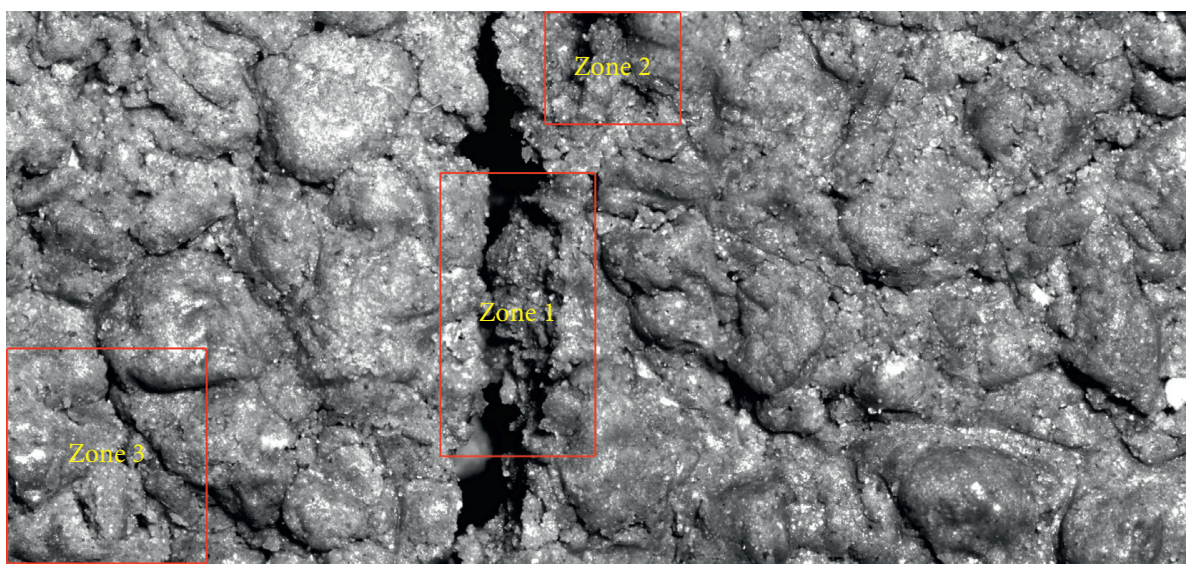

Figure 13: The processed image with large field.

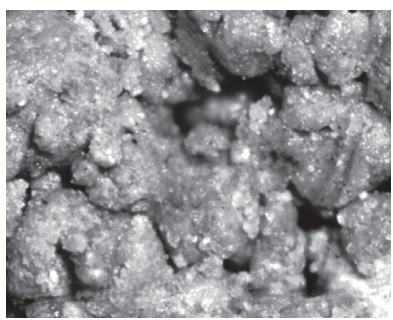

(a)

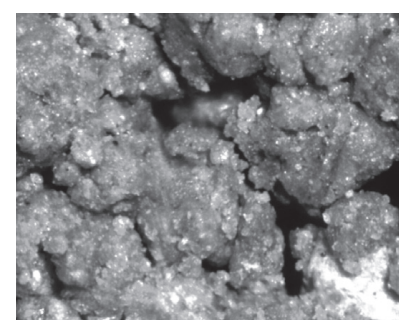

(b)

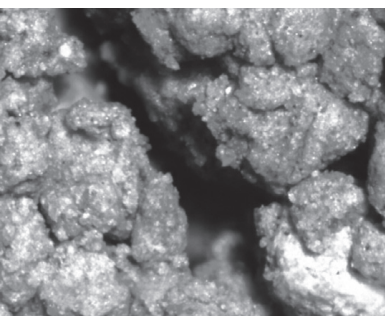

(e)

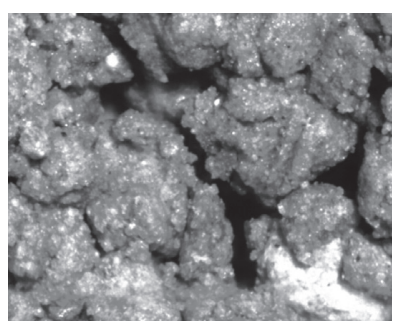

(c)

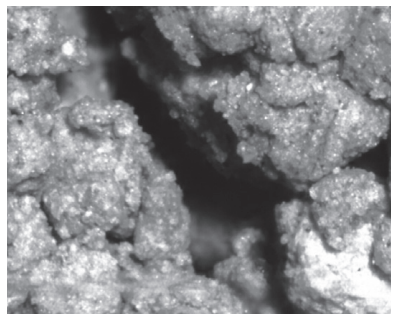

(f)

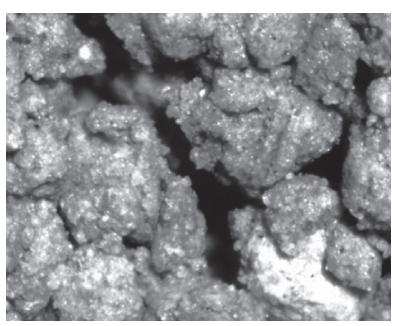

(d)

FIgURE 14: The continuous images under different tensile displacements in Zone 1: (a) $L=0.005 \mathrm{~mm}$; (b) $L=0.045 \mathrm{~mm}$; (c) $L=0.065 \mathrm{~mm}$; (d) $L=0.080 \mathrm{~mm}$; (e) $L=0.115 \mathrm{~mm}$; (f) $L=0.125 \mathrm{~mm}$.

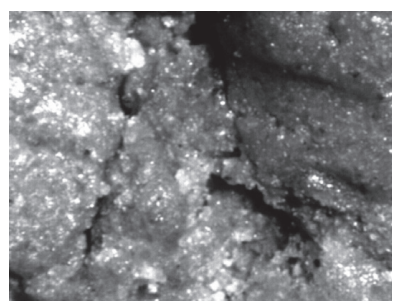

(a)

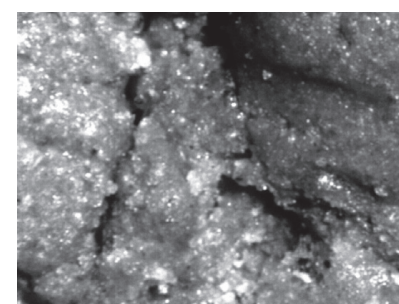

(b)

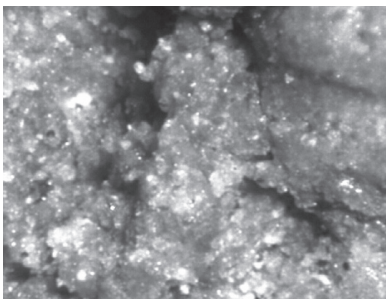

(e)

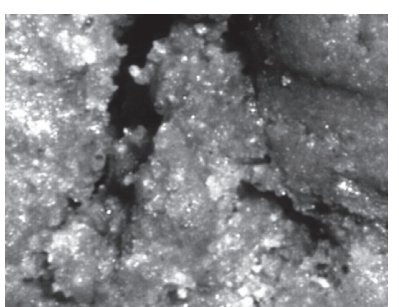

(c)

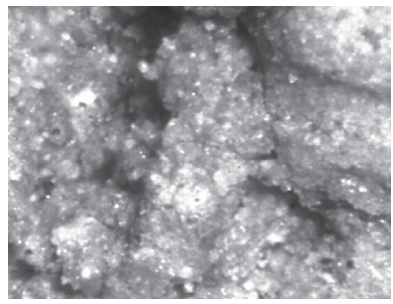

(f)

Figure 15: The continuous images under different tensile displacements in Zone 2: (a) $L=0.010 \mathrm{~mm}$; (b) $L=0.035 \mathrm{~mm}$; (c) $L=0.080 \mathrm{~mm}$; (d) $L=0.110 \mathrm{~mm}$; (e) $L=0.125 \mathrm{~mm}$; (f) $L=0.140 \mathrm{~mm}$. 


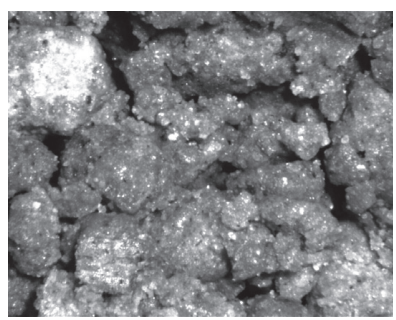

(a)

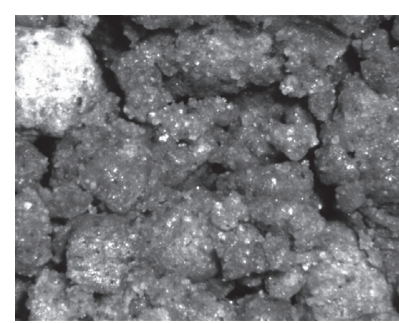

(b)

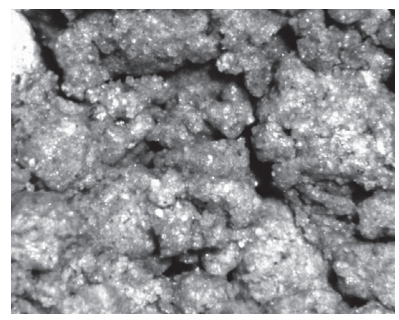

(e)

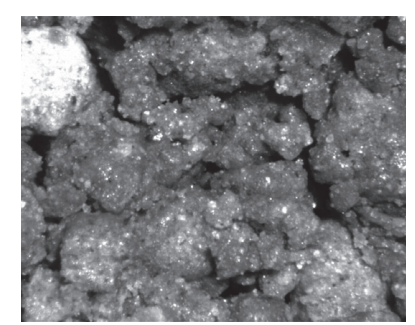

(c)

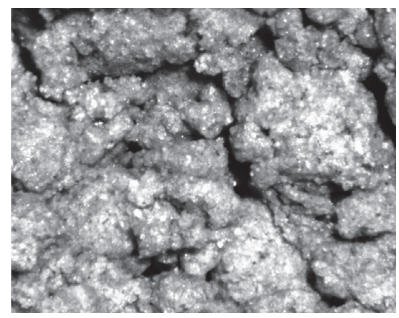

(f)

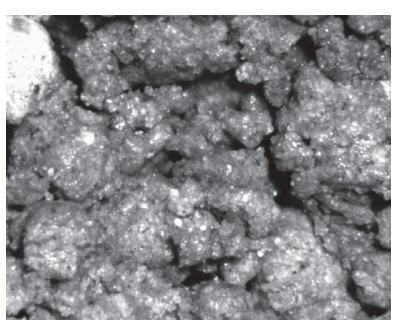

(d)

Figure 16: The continuous images under different tensile displacements in Zone 3: (a) $L=0.005 \mathrm{~mm}$; (b) $L=0.030 \mathrm{~mm}$; (c) $L=0.060 \mathrm{~mm}$; (d) $L=0.085 \mathrm{~mm}$; (e) $L=0.110 \mathrm{~mm}$; (f) $L=0.125 \mathrm{~mm}$.

pore distribution fractal dimension. Taking particle distribution fractal dimension as an example, the calculation method is as follows.

Firstly, calculate the length of each pixel according to the size and resolution of the image and divide the entire image by a square grid with a side length of $k$ pixels, so the side length of the grid can be expressed as follows:

$$
a=k \delta \text {, }
$$

where $a$ is the side length of the square grid, $\delta$ is the length of each pixel, and $k$ is the number of pixels on each side of the square grid.

Then, count the number of grids containing particles, which is expressed by $N(a)$. When the value of $k$ changes, such as $1,2,2^{2}, 2^{3}, \ldots, 2^{n}$, the value of $a$ will also change, which can be expressed by $a_{1}, a_{2}, a_{3}, \ldots, a_{n}$. Simultaneously, the number of grids containing particles also changes, expressed by $N_{1}, N_{2}, N_{3}, \ldots, N_{n}$.

Finally, fit the data points $\left(-\lg a_{n}, \lg N_{n}\right)$ linearly in the double logarithmic coordinate system, and the slope of the fitted line is the particle distribution fractal dimension, expressed by $D_{p}$. Generally speaking, the larger $D_{p}$, the more dispersed the particle distribution.

The definition of porosity is as follows:

$$
\Phi=\frac{S_{\mathrm{po}}}{S_{\mathrm{po}}+S_{\mathrm{pa}}},
$$

where $\Phi$ is the porosity, $S_{\mathrm{po}}$ is the pore area, and $S_{\mathrm{pa}}$ is the particle area.

When calculating the pore area, the image needs to be processed.

When calculating the values of $S_{p o}$ and $S_{p a}$, the image needs to be processed. We need to set a threshold firstly and then binarize the image according to the threshold. The value of $S_{p o}$ is the area where gray value is 0 while the value of
$S_{p a}$ is the area where gray value is 1 . One image processing example is shown in Figure 17.

4.2.1. Zone 1. Zone 1 is the main area of the test, and in order to obtain the regularity of mesostructural quantization parameters, six tests with different initial conditions were carried out. The changes of porosity and pore distribution fractal dimension during stretching are shown in Figures 18 and 19 , respectively.

From Figures 18 and 19, it can be seen that the porosity and pore distribution fractal dimension of all the six samples increase and show similar regularity. Firstly, the soil sample can bear the tensile stress through the cement between the particles, and the deformation is evenly distributed throughout the tensile section of the soil sample, so the change of soil structure is small. Then, the increment of tensile stress local structure will produce larger deformation due to the heterogeneity of soil sample, so the deformation will become local concentration from uniform distribution, which will cause the appearance of cracks, so the change of soil structure is obvious. Finally, with the increment of deformation, the cracks penetrate each other and form the main crack, and the main crack will penetrate the whole soil sample rapidly when the value of porosity and pore distribution fractal dimension will reach the maximum. Overall, the variety of the two parameters can be divided into three stages: stable stage, rapid change stage, and failure stage.

Similarly, the changes of particle orientation and particle distribution fractal dimension during stretching are shown in Figures 20 and 21, respectively. It can be seen that particle orientation increases while particle distribution fractal dimension decreases during stretching. The particles will adjust their structural direction to balance the external tensile load, so particle orientation will rise throughout the stretching process. On the other hand, the value of particle 


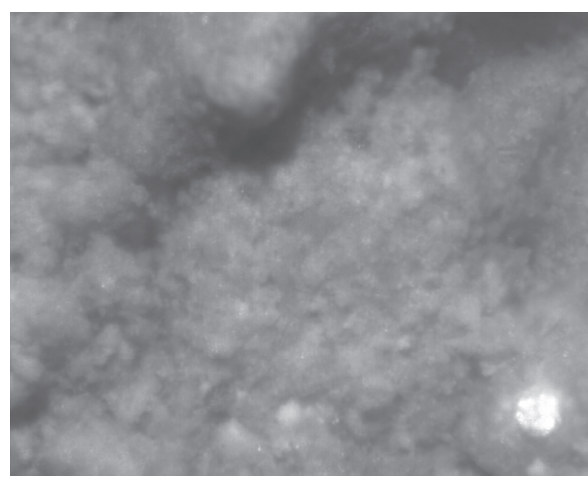

(a)

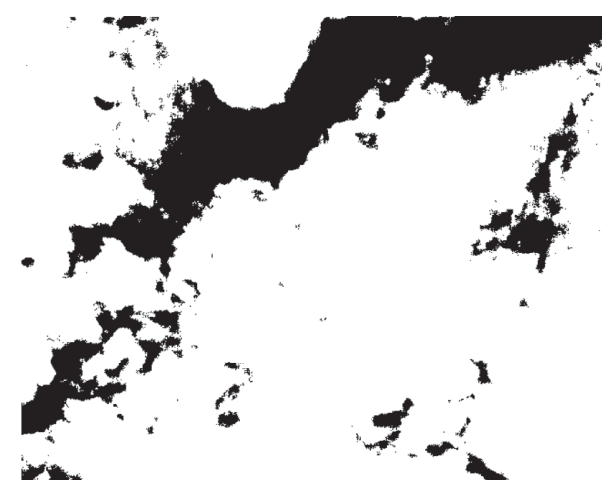

(b)

FIGURE 17: Binary image processing: (a) initial image; (b) binarized image.

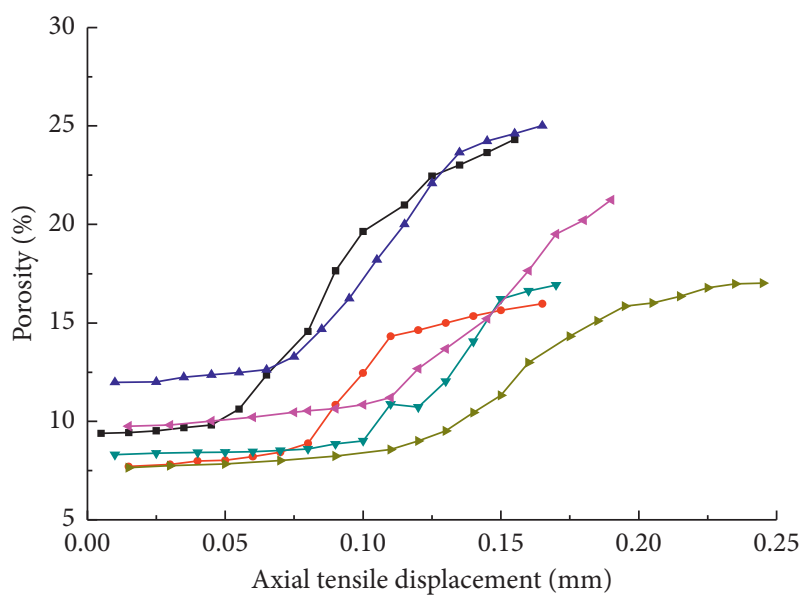

$\rightarrow C=85 \%, W=15.5 \% \rightarrow C=95 \%, W=17.5 \%$

$\longrightarrow C=100 \%, W=15.5 \% \quad \leftarrow C=95 \%, W=19.5 \%$

$\rightarrow C=90 \%, W=17.5 \% \rightarrow C=100 \%, W=21.5 \%$

FIgURE 18: The change of porosity in Zone 1.

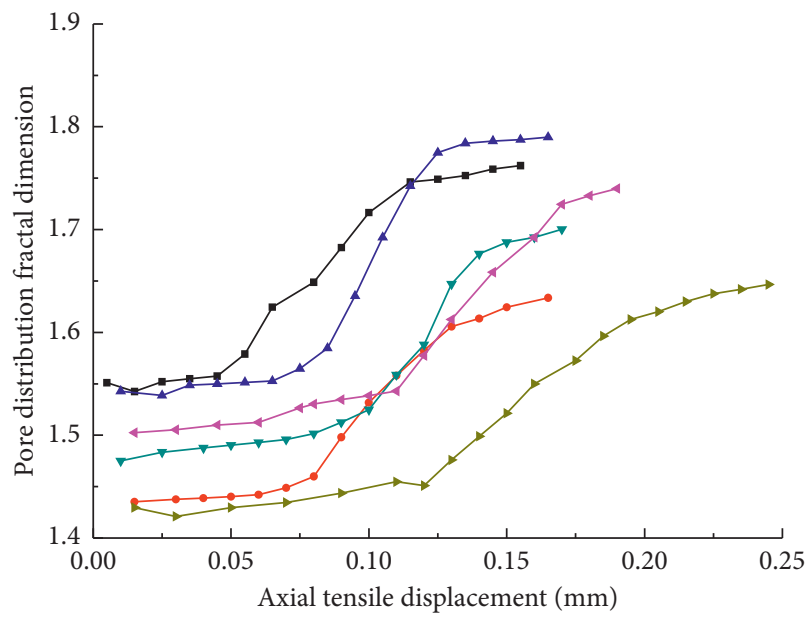

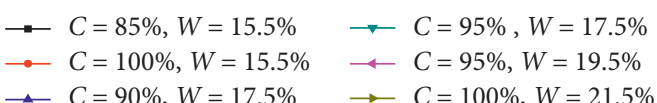

FIgURE 19: The change of pore distribution fractal dimension in Zone 1.
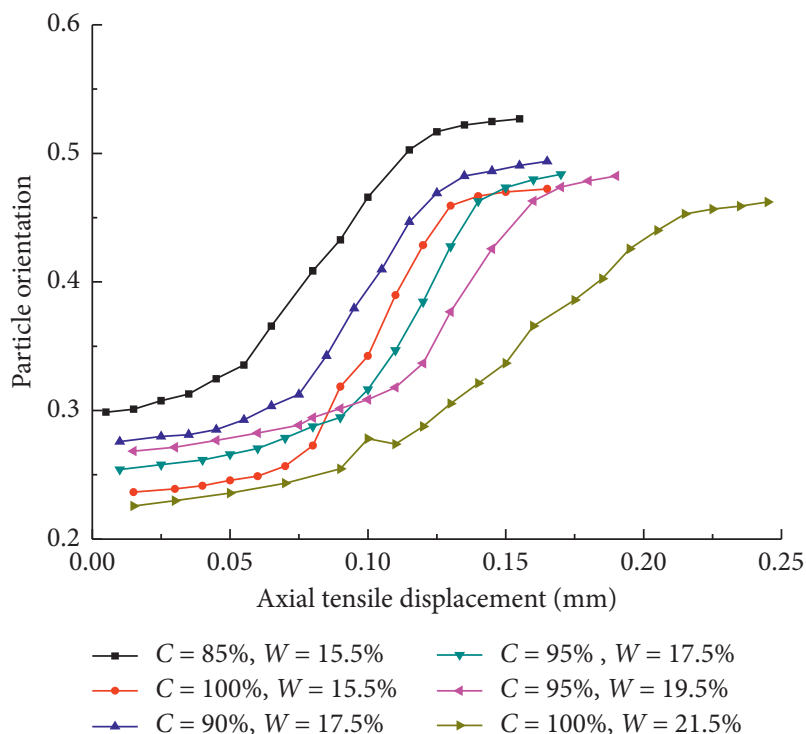

Figure 20: The change of particle orientation in Zone 1.

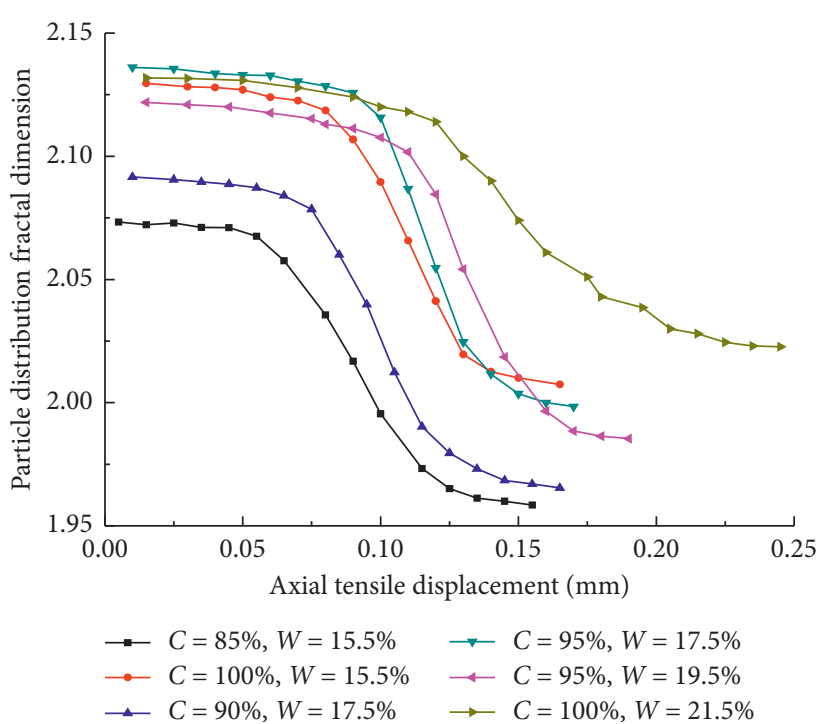

FIgURE 21: The change of particle distribution fractal dimension in Zone 1. 


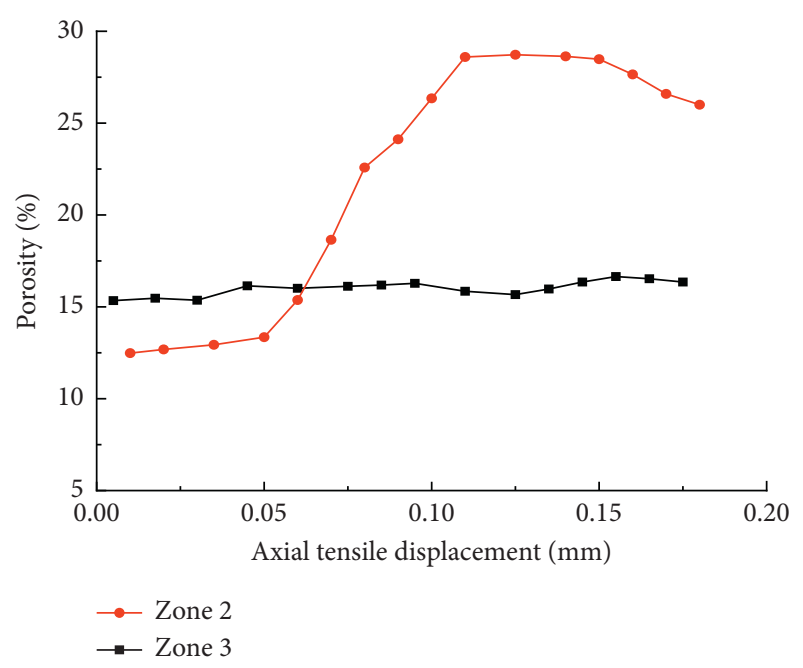

FIgUre 22: The change of porosity in Zone 2 and Zone 3.

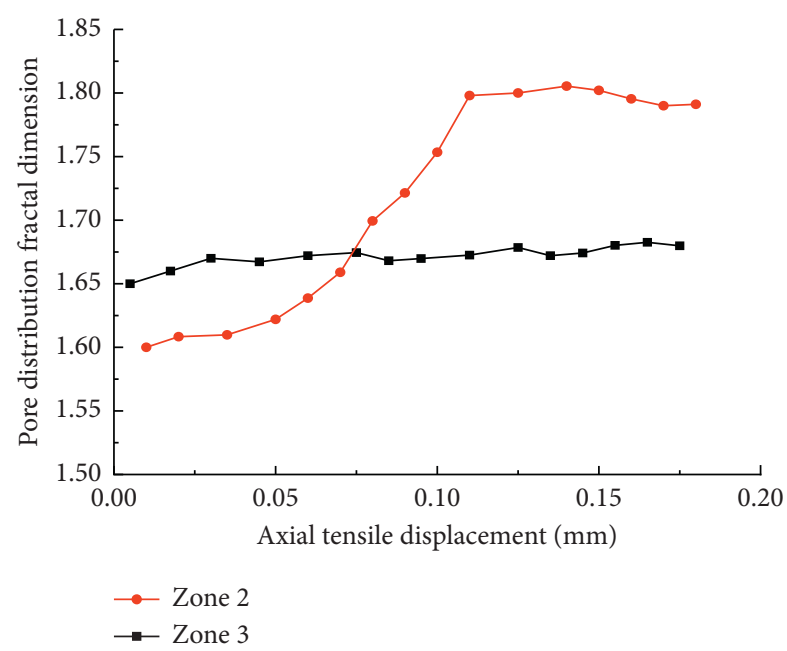

FIgURE 23: The change of pore distribution fractal dimension in Zone 2 and Zone 3.

distribution fractal dimension is related to the development of cracks, and the cracks will divide the particle aggregates, which can reduce the degree of particle grouping, so particle distribution fractal dimension will decrease throughout the stretching process. Meanwhile, we can see that the variety law of the two parameters is similar, and it can also be summarized into three stages: stable stage, rapid change stage, and failure stage.

4.2.2. Zone 2 and Zone 3. As the comparative tests, the changes of mesostructural quantization parameters in Zone 2 and Zone 3 also show good regularity. To present the results succinctly, each parameter was averaged using data for the six samples with different initial conditions. In addition, to compare and save space, the same parameter in Zone 2 and Zone 3 will be presented in the same figure. The

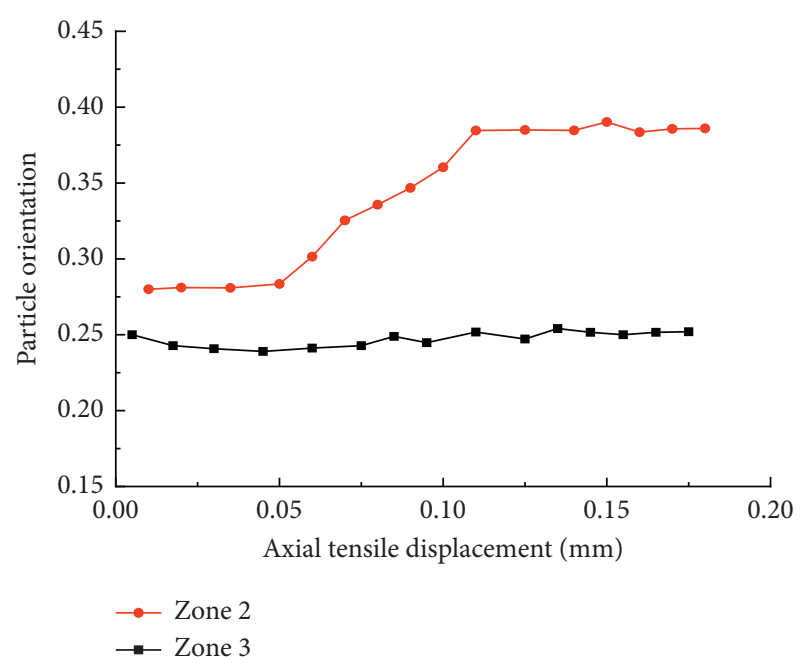

FIgURE 24: The change of particle orientation in Zone 2 and Zone 3.

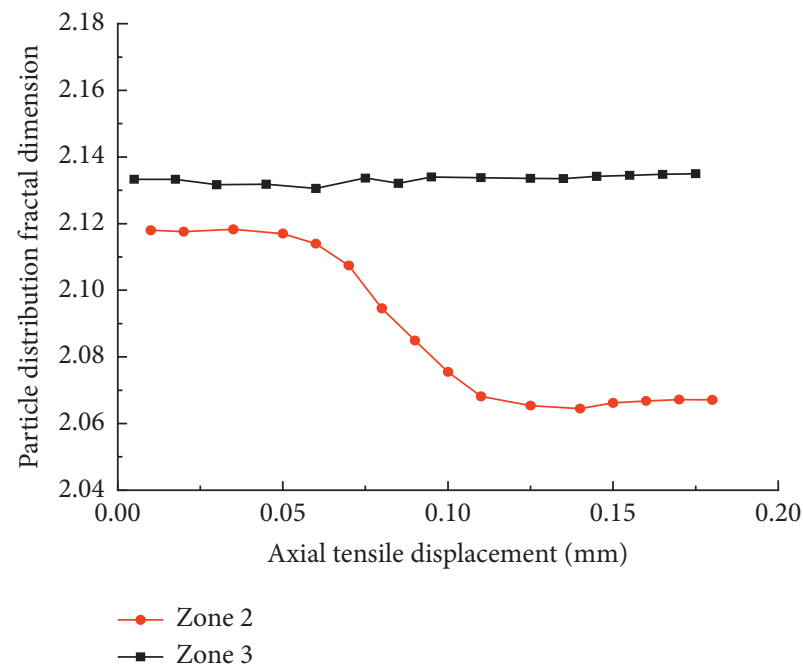

FIGURE 25: The change of particle distribution fractal dimension in Zone 2 and Zone 3.

changes of porosity and pore distribution fractal dimension in Zone 2 and Zone 3 are shown in Figures 22 and 23, respectively.

From Figures 22 and 23, it can be seen that the initial values of the two parameters in Zone 2 and Zone 3 are different, that is, because the value of parameter depends on the distribution of pores in the acquired image, and the soil sample is heterogeneous. In addition, the variety law of the two parameters in Zone 2 and Zone 3 is different, and the values of the two parameters in Zone 3 remain essentially constant while that in Zone 2 changes significantly. During the whole stretching process, the deformation of soil sample is first uniformly distributed and then locally concentrated, so the crack will not develop in most areas including Zone 3, and the two parameters in Zone 3 are basically unchanged. On the other hand, the cracks will develop in Zone 2, but they will stop developing after the main crack is formed and 
have a small rebound, so the two parameters in Zone 2 remain stable firstly and then increase rapidly, and after that there will be a small drop.

Similarly, the changes of particle orientation and particle distribution fractal dimension in Zone 2 and Zone 3 are shown in Figures 24 and 25, respectively. The cracks do not develop in Zone 3, so the particle structure and corresponding parameters in Zone 3 remain unchanged basically. However, with the development of cracks in Zone 2, the particles will adjust their structure firstly and then be divided by cracks, which lead to the reduction of particle aggregates, so particle orientation increases while particle distribution fractal dimension declines in Zone 2. In addition, the changes of parameters in Zone 2 show a similar law with that in Zone 1, but the variation is smaller due to the cessation of cracks.

4.3. Discussion. So far, the research on tensile characteristics of soil has mainly focused on macroscopic tensile strength, such as the test methods and influencing factors of tensile strength, but the micro and meso-scopic research on the changes of structural form and quantitative parameters during the whole tensile process is rarely involved. The research in this article draws on the method and theory in the study of the shear zone. The testing system developed in this paper can realize the continuous acquisition of mesostructural image, but the image quality and magnification are not as good as that captured by the static observation method, such as SEM. Next, the work of image processing and theoretical analysis such as three-dimensional visualization of images, precision of quantitative parameters, and constitutive model of tensile failure needs to be further carried out.

\section{Conclusions}

The following conclusions can be drawn from the experimental work presented in this paper:

(1) By the developed test system, we can capture the mesostructural images of the soil sample continuously at different stages in the stretching process, obtain the clear global image including all observation areas, and extract the quantitative parameters of the mesostructural features by using image processing technology. Based on these, we can analyze the mesostructural changes in different areas.

(2) In the initial stage of stretching, the deformation is evenly distributed throughout the tensile section of the soil sample, and there is no crack, so the mesostructural form and quantitative parameters remain unchanged basically. Then, the cracks start to appear and develop rapidly with the increment of tensile stress, and now the deformation becomes local concentration from uniform distribution. After the main crack is formed, the surrounding cracks stop developing and have a small rebound. Finally, the main crack penetrates the entire soil sample, which means the tensile failure, and the mesostructural form and quantitative parameters reach the extremum and no longer change.

(3) According to the changes of mesostructural form and quantitative parameters in Zone 1, it can be divided into three stages: stable stage, rapid change stage, and failure stage. The variety law of the mesostructural form and quantitative parameters in Zone 2 is similar to that in Zone 1, but the variation is smaller due to the cessation of cracks. The mesostructural form and quantitative parameters in Zone 3 remain unchanged basically during the whole stretching process.

\section{Data Availability}

The experimental data used to support the findings of this study are included in the article.

\section{Conflicts of Interest}

The authors declare that they have no conflicts of interest.

\section{Acknowledgments}

This work was supported by the Science and Technology Research Program of Jiangxi Provincial Education Department (GJJ180929), Provincial Natural Science Foundation of Hunan (20JJ30581), Scientific Research Fund of Hunan Provincial Education Department (19A034), Key Laboratory of Hydraulic and Waterway Engineering of the Ministry of Education, Chongqing Jiaotong University (SLK2017B02), Key Project of Natural Science Foundation of Jiangxi Province (20202ACBL204016), and National Natural Science Foundation of China (51609114 and 51769016).

\section{References}

[1] I. Vanicek, "The importance of tensile strength in geotechnical engineering," Acta Geotechnica Slovenica, vol. 10, pp. 5-17, 2013.

[2] S. B. Tamrakar, T. Mitachi, and Y. Toyosawa, "Measurement of soil tensile strength and factors affecting its measurements," Soils and Foundations, vol. 47, no. 5, pp. 911-918, 2007.

[3] S. B. Tamrakar, Y. Toyosawa, T. Mitachi, and K. Itoh, "Tensile strength of compacted and saturated soils using newly developed tensile strength measuring apparatus," Soils and Foundations, vol. 45, no. 6, pp. 103-110, 2005.

[4] H. Trabelsi, M. Jamei, H. Zenzri, and S. Olivella, "Crack patterns in clayey soils: experiments and modeling," International Journal for Numerical and Analytical Methods in Geomechanics, vol. 36, no. 11, pp. 1410-1433, 2012.

[5] L. D. Suits, T. C. Sheahan, and L. F. Vesga, "Direct tensileshear test (DTS) on unsaturated kaolinite clay," Geotechnical Testing Journal, vol. 32, pp. 397-409, 2009.

[6] S. Akagawa and K. Nishisato, "Tensile strength of frozen soil in the temperature range of the frozen fringe," Cold Regions Science and Technology, vol. 57, no. 1, pp. 13-22, 2009.

[7] A. A. DePhilippe, "Tensile strength of disturbed and recompacted soils (pilot tests)," Doctoral Dissertation, Princeton University, Princeton, NJ, USA, 1952. 
[8] G. P. Tschebotarioff, E. Ward, and A. A. DePhilippe, "The tensile strength of disturbed and recompacted soils," in Proceedings of the 3rd International Conference on Soil Mechanics and Foundation Engineering, vol. 3, pp. 207-210, Zürich, Switzerland, August 1953.

[9] C.-S. Tang, D.-Y. Wang, Y.-J. Cui, B. Shi, and J. Li, "Tensile strength of fiber-reinforced soil," Journal of Materials in Civil Engineering, vol. 28, no. 7, 2016.

[10] P. V. Divya, B. V. S. Viswanadham, and J. P. Gourc, "Evaluation of tensile strength-strain characteristics of fiber-reinforced soil through laboratory tests," Journal of Materials in Civil Engineering, vol. 26, pp. 14-23, 2013.

[11] T.-H. Kim and S. Sture, "Capillary-induced tensile strength in unsaturated sands," Canadian Geotechnical Journal, vol. 45, no. 5, pp. 726-737, 2008.

[12] N. Lu, B. Wu, and C. P. Tan, “Tensile strength characteristics of unsaturated sands," Journal of Geotechnical and Geoenvironmental Engineering, vol. 133, no. 2, pp. 144-154, 2007.

[13] A. Mesbah, J. C. Morel, P. Walker, and K. Ghavami, "Development of a direct tensile test for compacted earth blocks reinforced with natural fibers," Journal of Materials in Civil Engineering, vol. 16, no. 1, pp. 95-98, 2004.

[14] H. Nahlawi, S. Chakrabarti, and J. Kodikara, "A direct tensile strength testing method for unsaturated geomaterials," Geotechnical Testing Journal, vol. 27, pp. 1-6, 2004.

[15] H.-D. Li, C.-S. Tang, Q.-L. Xu, C.-L. Liu, T. Leng, and B. Shi, "Advances in experimental testing methods of soil tensile strength," Rock and Soil Mechanics, vol. 37, pp. 175-186, 2016.

[16] N. C. Consoli, R. R. de Moraes, and L. Festugato, "Parameters controlling tensile and compressive strength of fiber-reinforced cemented soil," Journal of Materials in Civil Engineering, vol. 25, no. 10, pp. 1568-1573, 2013.

[17] S. Huang, K. Xia, F. Yan, and X. Feng, "An experimental study of the rate dependence of tensile strength softening of longyou sandstone," Rock Mechanics and Rock Engineering, vol. 43, no. 6, pp. 677-683, 2010.

[18] T. F. Azmatch, D. C. Sego, L. U. Arenson, and K. W. Biggar, "Tensile strength and stress-strain behaviour of Devon silt under frozen fringe conditions," Cold Regions Science and Technology, vol. 68, no. 1-2, pp. 85-90, 2011.

[19] C.-S. Tang, X. Pei, D. Wang, and B. Shi, "Tensile strength of compacted clayey soil," Journal of Geotechnical and Geoenvironmental Engineering, vol. 141, pp. 1-8, 2015.

[20] C.-S. Tang, D.-Y. Wang, Y.-J. Cui, B. Shi, and J. Li, “Tensile strength of fiber-reinforced soil," Journal of Materials in Civil Engineering, vol. 7, Article ID 04016031, 2016.

[21] M. Cui, S.-Y. Han, and B.-N. Hong, "Development and application of a new geotechnical device for direct tension test," Rock and Soil Mechanics, vol. 38, pp. 1832-1840, 2017.

[22] M. Cui, B.-N. Hong, and J. Liu, "Development and experimental research of sample preparation device for new uniaxial tensile specimen," Journal of Sichuan University (Engineering Science Edition), vol. 48, pp. 64-69, 2016.

[23] H.-B. Lü, Z.-T. Zeng, R.-D. Ge, and Y.-L. Zhao, "Experimental study of tensile strength of swell-shrink soils," Rock and Soil Mechanics, vol. 34, pp. 615-620, 2013.

[24] A. Satoshi and N. Kohei, "Tensile strength of frozen soil in the temperature range of the frozen fringe," Cold Regions Science and Technologyogy, vol. 57, pp. 13-22, 2009.

[25] X.-T. Zhang, Q.-Y. Zhang, Q. Gao, W. Xiang, C. Wang, and S. B. Yuan, "Development and application of geotechnical direct tension test devices," Chinese Journal of Geotechnical Engineering, vol. 36, pp. 1309-1315, 2014.
[26] C.-H. Zhu, J.-M. Liu, B.-W. Yan, and J.-L. Ju, "Experimental study on relationship between tensile and shear strength of unsaturation clay earth material," Chinese Journal of Rock Mechanics and Engineering, vol. 27, pp. 3453-3458, 2008.

[27] M. g. Hwang, S. m. Kim, and D. h. Har, "A method of identifying digital images with geometric distortion," Australian Journal of Forensic Sciences, vol. 49, pp. 93-105, 2016.

[28] L. E. Carvalho, A. C. Sobieranski, and A. von Wangenheim, "3D segmentation algorithms for computerized tomographic imaging: a systematic literature review," Journal of Digital Imaging, vol. 31, no. 6, pp. 799-850, 2018.

[29] S. Shirly and K. Ramesh, "Review on 2D and 3D MRI image segmentation techniques," Current Medical Imaging Formerly Current Medical Imaging Reviews, vol. 15, no. 2, pp. 150-160, 2019.

[30] D. Al-Jeznawi, M. Sanchez, and A. J. Al-Taie, "Using image analysis technique to study the effect of boundary and environment conditions on soil cracking mechanism," Geotechnical and Geological Engineering, vol. 39, no. 1, pp. 25-36, 2021.

[31] K. Sui and H.-G. Kim, "Research on application of multimedia image processing technology based on wavelet transform," EURASIP Journal on Image and Video Processing, vol. 24, pp. 1-9, 2019.

[32] B. P. Wen and A. Aydin, "Mechanism of a rainfall-induced slide-debris flow: constraints from microstructure of its slip zone," Engineering Geology, vol. 78, no. 1-2, pp. 69-88, 2005.

[33] M. Cui, J. Liu, S.-Y. Han, and B.-N. Hong, "Development and application of microstructure change test system in the process of soil tensile failure," Rock and Soil Mechanics, vol. 39, pp. 4278-4286, 2018. 